\title{
Progressive sensory neuropathy in children
}

\author{
R. H. JOHNSON AND J. M. K. SPALDING
}

From the Department of Neurology, United Oxford Hospitals

Children who have sensory loss sufficient to cause neuropathic (Charcot) joints have often been diagnosed as having congenital indifference to pain but, as Ogden, Robert, and Carmichael (1959) have emphasized, this condition must be distinguished from sensory neuropathy. In a patient with congenital indifference to pain stimuli which are painful to a normal subject are not felt on any part of the body to be disagreeable; nevertheless pin pricks can be identified and localized, and other stimuli, including temperature, are normally perceived (Critchley, 1956). In the patient with a sensory neuropathy however, modalities of sensation other than pain are also involved and the trunk is usually spared. Sensory neuropathy may be familial with dominant inheritance (Hicks, 1922; Denny-Brown, 1951; Heller and Robb, 1955; Reimann, McKechnie, and Stanisavljevic, 1958; Mandell and Smith, 1960). It may also occur sporadically and some cases, mainly in adults, have been delineated into distinct groups such as those associated with neoplasms (DennyBrown, 1948) and those which are not progressive (Ogden, Robert, and Carmichael, 1959).

We report two patients whose disability in early childhood led to the diagnosis of congenital indifference to pain but who subsequently proved to have a progressive sensory neuropathy. Evidence is presented that the neuropathy does not belong to any of the generally recognized groups of sensory neuropathy.

\section{CASE 1}

I.P. (R.I. 197380) was a 10-year-old boy. His father was half brother of his mother, his parents having a common mother. There is no other relevant family history. Delivery was normal and at full term, and birth weight was $8 \mathrm{lb} .1 \mathrm{oz}$. (3.6 kg.). He sat up at 6 months, stood at 2 years, walked at 3 years, and talked at $3 \frac{1}{2}$ years. At 5 years of age the patient was admitted to another hospital with ulcers on his feet. He was thought to have congenital indifference to pain, and joint sense and vibration sense were described as normal. When 6 years of age he was seen by two neurologists, who found no loss of sensation except of pain. When 8 years of age he was first seen at United Oxford Hospitals and had an infection of the right big toe, which ultimately resulted in amputation a year later. At 10 years of age, he was admitted with a spiral fracture of the left tibia, which caused him only slight pain. He could, however, experience abdominal pain and headaches.

When we examined him he was 10 years of age. He was able to write adequately and speak well and his intelligence was normal (I.Q. 107, Weschler intelligence scale for children). He was $4 \mathrm{ft} .4 \frac{1}{2} \mathrm{in} .(133 \mathrm{~cm}$.) in height
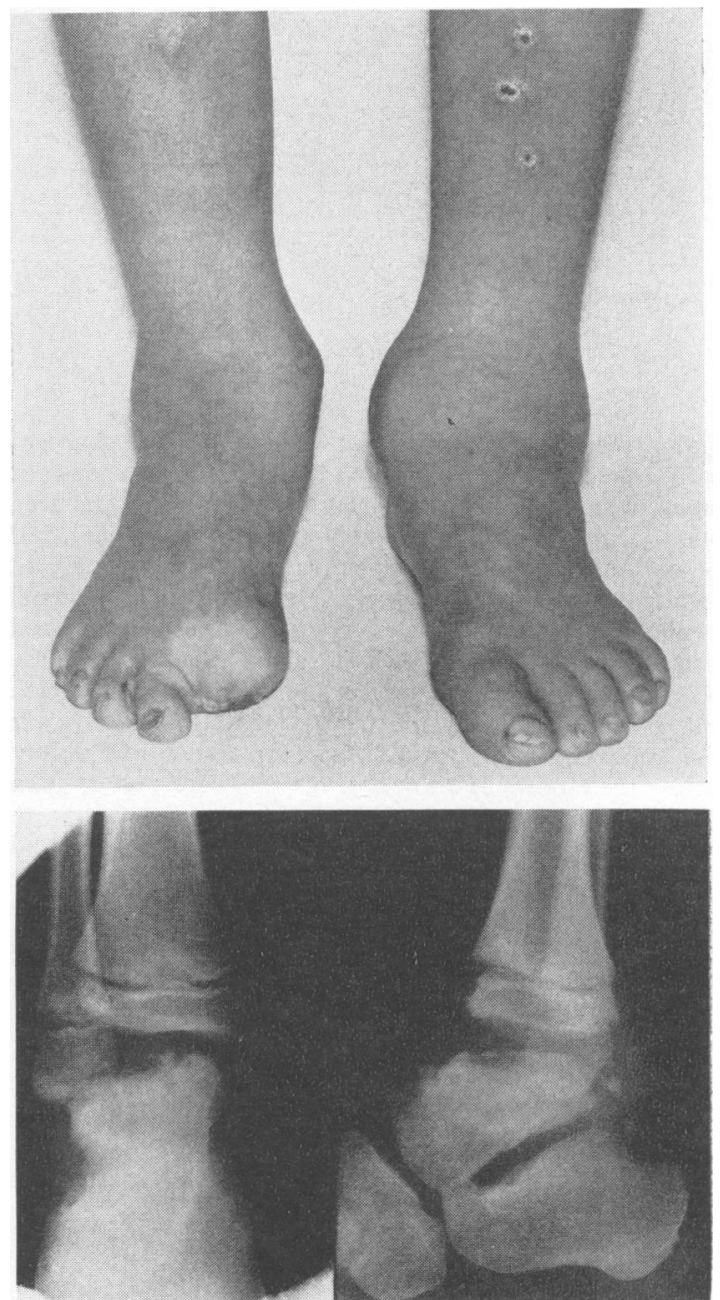

FIG. 1. The ankles and feet of case 1 (I.P.) and radiological changes in the right ankle. 
FIG. 2. Sensory chart of case 1 (I.P.) showing touch, pinprick, temperature, and reflex abnormalities. Dark shading on the extremities indicates loss of digits.

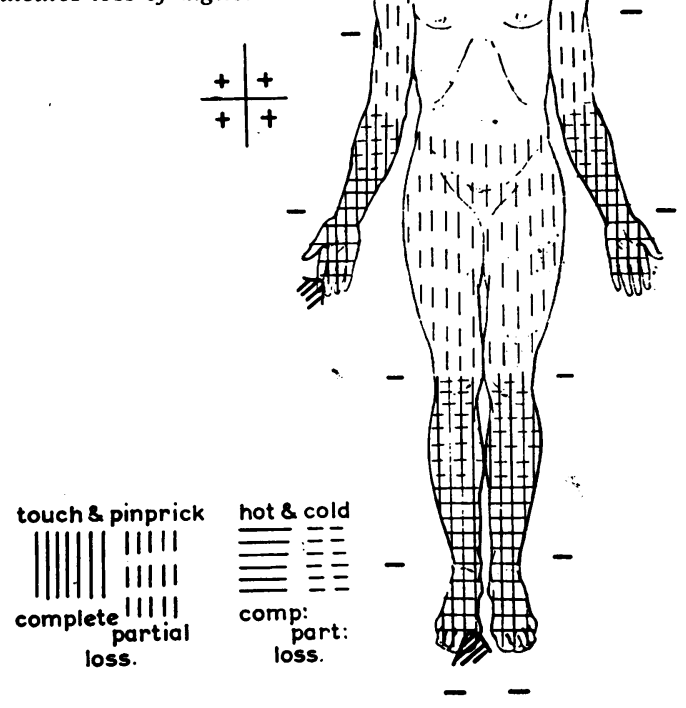
$++t$



and 4 stone $3 \mathrm{lb}$. (27 kg.) in weight (normal average: $4 \mathrm{ft} .7$ in. $(140 \mathrm{~cm}$.), 5 stone $2 \mathrm{lb}$. $(33 \mathrm{~kg}$.)). His sense of smell, taste, vision, and sensation in the trigeminal area was normal. There were many scars on the distal half of all limbs. The fingers were short and spade shaped, and radiographs showed partial destruction of the distal phalanges. Ankle joints were thickened and disorganized (Fig. 1) and the site of amputation of the right big toe was discharging. Sensation to pinprick and light touch was present over face and trunk but was impaired over the upper arms, thighs, and lower abdomen and absent below the elbows and knees (Fig. 2). There was no pain on pressing the tendo Achillis. Temperature sensation to stimuli of approximately $20^{\circ} \mathrm{C}$. and $55^{\circ} \mathrm{C}$. was impaired distal to elbows and knees and absent distal to the middle of the forearms and shins. Joint position sense was impaired at wrists and ankles and absent in fingers and toes. There was no muscular wasting or weakness. Tendon and plantar reflexes were absent (right big toe missing). Abdominal reflexes were brisk.

INVESTIGATIONS At 6 years of age blood urea, liver function tests, serum alkaline phosphatase, and serum phosphorus were normal.

At 10 years of age cerebrospinal fluid and an electroencephalogram were normal. Chromasomes were normal in the skin on culture. Chromatography of the urine revealed no abnormal amino-acids.

Cranial nerves An audiogram showed a slight conductive deafness, particularly for high tones, on both sides. Caloric responses to water at $44^{\circ} \mathrm{C}$. and $30^{\circ} \mathrm{C}$. were normal. An intravenous injection of lobeline hydro $\mathbb{Q}$ chloride $(0.2 \mathrm{mg}$.) made him cough within six seconds and this indicates that the sensory supply of the carotide body via the glossopharyngeal nerve was intacs (Berliner, 1940).

Peripheral sensory nerves Intradermal injection of histamine $(0.05 \mathrm{mg}$.) on the chest caused a normaf triple response. Similar injections on the forearms andêt lower legs produced a local reaction at the site of injection without, however, the flare component of the triple response. The flare is an axone reflex in pain fibreses (Folkow, 1955) and its absence distally confirmed the clinical findings of loss of sensation to pain in the dista parts of the limbs and indicated that the lesion lay in peripheral nerve. To assess ischaemic muscle pain, a cuff on the upper arm was inflated with a pressure abovee the systolic blood pressure, and the patient clenched and released his fist about 60 times per minute. Slight pain occurred after four or five minutes in the forearm? muscles. In normal subjects this occurs in less than one minute.

Autonomic nerves The patient was warmed with a heat cradle, and sweating, indicated by quinizarin powder (Guttmann, 1940), occurred normally on face, trunk, and extremities. When his hand was placed in ice water. piloerection occurred over the forearm. Intraderma $N$ injection of acetylcholine $(10 \mathrm{mg}$.) and faradism to the skin both produced local piloerection, even on the forearms and lower legs where sensory loss was severe These observations indicate that post-ganglionic sy- pathetic fibres subserving sweating and piloerection were intact (Bárány and Cooper, 1956).

The blood pressure was recorded with an inta arterial needle and a capacitance manometer system. normal response was obtained to an acute rise in intra + thoracic pressure (Valsalva's manoeuvre) indicating both that the afferent nerves from the arterial baroreceptors and the vasomotor nerves on the efferent side of the arc were intact. No change in blood pressure was, however, obtained when a hand was put in cold water at $0-4^{\circ} \mathrm{C}$. In the normal subject this causes a rise in blood pressure and pulse pressure, and the absence of this response in $\vec{a} \vec{\sigma}$ subject whose efferent vasomotor mechanisms are intace suggests that the afferent side of the arc was blocked. On heating the trunk with a radiant heat cradle, there was ac rapid increase in heat elimination from the fingers.observed with heat flow discs (Hatfield, 1950). The response indicates active efferent vasomotor nerves tợ the fingers.

Electromyographic studies Normal innervation was found for muscles supplied by the ulnar and mediab popliteal nerves, and the conduction velocity of the ulnars nerve was normal $(52 \mathrm{~m}$./sec.). Monosynaptic reflexeso could not be obtained on stimulation of the mediaP popliteal nerve in the popliteal fossa, nor could sensory action potentials be obtained from the lateral popliteaE. nerve. These findings are consistent with the peripheraN sensory loss found clinically.

\section{CASE 2}

R.B. (R.I. 199590) was seen at the ages of 7 and 15 years 
His mother and father were first cousins and he was an only child. There is no other relevant family history and there was no relationship with case 1. Delivery was normal and at full term and birth weight was $7 \frac{1}{2} \mathrm{lb}$. $(3.4 \mathrm{~kg}$.). He walked at $1 \frac{1}{2}$ years and talked at 2 years. When he was 9 months old he burnt his hand and apparently experienced pain. About a year later, however, his mother began to notice that he did not cry if he burned his hands and since then he has had many painless injuries and infections of his hands.

At 3 years of age he developed a painless ulcer on the right big toe, which did not heal for two years. At 6 years of age his left ankle was found to be disorganized, and he spent most of the next three years in hospital elsewhere and during this time an ulcer developed on the left foot which has not healed. A diagnosis of congenital indifference to pain was made. At 7 years of age the tips of his fingers were scarred and some were shortened. Sensation to pinprick and light touch was absent below the elbow and defective below the shoulders and hips (Fig. 3). Position sense was absent in the digits and defective in the wrists and ankles but normal in the elbows and knees. Temperature sensation was impaired in the hands and present on the forearm. Limb and abdominal reflexes were absent.

At 15 years of age he was able to speak well, but educationally was backward. His intelligence quotient was 81 (Wechsler scale for children) but allowance must be made for his deprivation of education. He was $4 \mathrm{ft}$. $10 \mathrm{in}$. in height $(147 \mathrm{~cm}$.$) and 5 \mathrm{st} .8 \mathrm{lb} .(35 \mathrm{~kg}$. $)$ in weight

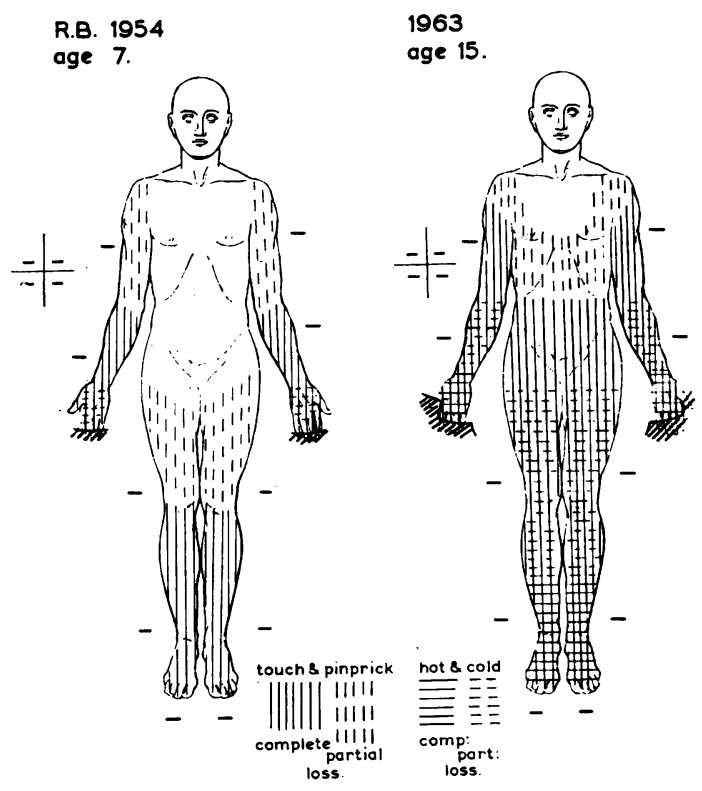

FIG. 3. Sensory chart of case 2 (R.B.) showing touch, pinprick, temperature, and reflex abnormalities at 7 and 15 years of age. Dark shading on the extremities indicates loss of digits. (normal average: $5 \mathrm{ft} .6 \mathrm{in}$. (168 cm.) $8 \mathrm{st} .8 \mathrm{lb} .(54.5 \mathrm{~kg}$.$) ).$ His sense of smell, taste, vision, and sensation in the trigeminal area was normal.

Nothing remained of the fingers beyond the proximal phalanges and of the thumbs beyond the metacarpals (Fig. 4). The left ankle was disorganized (Fig. 5) and inverted; he could not walk on it and had used crutches for three years. His sensory abnormalities had extended proximally. Sensation of pinprick and light touch was absent distal to the shoulders and below the costal margins (Fig. 3). Deep pain was absent on pressure on the



FIG. 4. The hands of case 2 (R.B.) at 15 years of age and radiological changes in the right hand. 



FIG. 5. The ankles and feet of case 2 (R.B.) and radiological changes in the left ankle.

tendo Achillis. Position sense was absent in the wrists and the ankles but normal in elbows and knees. Vibration was felt on the sternum but not on the limbs or on the iliac crests. Temperature sensation to stimuli at $20^{\circ} \mathrm{C}$. and $50^{\circ} \mathrm{C}$. was absent below the wrists and over the feet and the lower third of the shins. It was defective to stimuli at $20^{\circ} \mathrm{C}$. and $37^{\circ} \mathrm{C}$. over the rest of the forearms and the lower limbs. Limb and abdominal reflexes were $Z$ absent.

INVESTIGATIONS At the age of 7 years, cerebrospinal fluid was normal.

At the age of 15 years, chromatography of the urine 0 revealed no abnormal amino-acids. An electroencephalogram was normal. Chromosomes were normal in skin $\frac{\bar{\partial}}{\bar{\partial}}$ and blood on culture.

Eighth cranial nerve Audiograms and caloric responses. to water at $44^{\circ} \mathrm{C}$. and $30^{\circ} \mathrm{C}$. were normal.

Peripheral sensory nerves In an area of normal sensation on the chest, a normal reaction to an intra-므 dermal injection of histamine was obtained. In the $\overline{\bar{\sigma}}$ anaesthetic areas, however, intradermal injection of $\frac{\bar{\omega}}{\bar{s}}$ histamine produced only a local reaction around the site $\mathbb{\Phi}$ of injection and a flare did not appear. Slight ischaemic $\frac{\Omega}{\partial}$ muscle pain was produced in one minute if he clenched $\$$ and released his fist when a cuff was inflated above $\overrightarrow{0}$ systolic pressure on the upper arm. Biopsy from the left foot showed nerve bundles which appeared degenerate $\vec{\omega}$ with scanty thickened axones and surrounded by dense? fibrous tissue.

Autonomic nerves $\mathrm{He}$ was able to sweat in the anaesthetic areas but did not sweat on the palms. Intradermal injection of acetylcholine $(10 \mathrm{mg}$.) causediv piloerection around the site of injection over the forearms and shins and this response was normal. His blooder pressure was maintained normally on putting himo vertical and there was a normal response to Valsalvg's manoeuvre. When the trunk was heated with a radian heat cradle, some vasodilatation, observed with heat-fl\&ి음 discs (Hatfield, 1950), occurred in the stumps of fingers. These tests showed no disturbance of sudomot $\vec{\theta}$ piloerector, or vasomotor functions.

Electromyographic studies Normal innervation was found for muscles supplied by the ulnar and poplitealo nerves, and the conduction velocity of the ulnar nerves was within normal limits $(61.5$ to $65 \mathrm{~m}$./ $/ \mathrm{sec}$.). Mono-o synaptic reflexes could not be obtained on stimulation of the medial popliteal nerve in the popliteal fossa, nor could sensory action potentials be obtained from the lateral popliteal nerve. These findings are consistent with the peripheral sensory loss found clinically.

\section{DISCUSSION}

These patients had a sensory peripheral neuropathy as shown by the clinical picture, local response to intradermal histamine, and nerve biopsy. Thei sensory loss involved all modalities, first manifested itself in the distal parts of the limbs in the first two years of life and became gradually more severe and? more extensive. There was no motor or autonomie involvement. Van Bogaert (1957), writing about. neurogenic ulceration, laid stress on changes in the vascular system but we have been unable to demon strate vascular abnormalities in our patients Sporadic sensory neuropathy has been reported in children by a number of authors (Head, 1903\% 
Parks and Staples, 1945; Eyckmans, Radermecker, and Van Bogaert, 1956; Munro, 1956; Wadia and Dastur, 1960; Winkelmann, Lambert, and Hayles, 1962), and one of these patients had parents who were first cousins (Parks and Staples, 1945). In both cases reported here the parents were closely related but unaffected and this suggests an abnormality transmitted as a recessive trait.

DISTINCTION FROM CONGENITAL INDIFFERENCE TO PAIN Congenital indifference to pain (Table I) is an important differential diagnosis because patients with congenital indifference to pain also present in early childhood and sometimes have consanguineous parents (Durand and Belotti, 1957; Fanconi and Ferrazzini, 1957). The original description was by Dearborn (1932) and such cases as those reported by Westlake (1952), Fanconi and Ferrazzini (1957), and Silverman and Gilden (1959) are good examples of this condition.

Case 1 at the age of 5 years appeared to have loss of pain sensation only and both patients were originally diagnosed as having congenital indifference to pain. In sensory neuropathy, however, other modalities of sensation are involved as well as pain and this is peripheral in distribution, whereas in congenital indifference to pain there is only pain loss and the whole body is involved from the beginning. It is therefore of particular importance in the differential diagnosis to determine whether the loss of pain sensation extends to the head and trunk. Other features which may distinguish sensory neuropathy from congenital indifference to pain are absence of tendon reflexes, progression of the neurological findings, absence of flare response to intradermal injection of histamine in an area of sensory loss, and peripheral nerve degeneration on biopsy (Ogden et al., 1959). We agree with Critchley (1956) and Ogden et al. (1959) that cases with severe mental defect or with sensory loss to modalities other than pain should not now be described as having congenital indifference to pain. An additional chromosome of group 13 to 15 has been found in two unrelated patients with congenital indifference to pain (Beçak, Beçak, and Schmidt, 1963). Chromosome studies in our patients were normal.

DISTINCTION FROM HEREDITARY SENSORY RADICULAR NEUROPATHY Some sporadic cases of sensory neuropathy have been described as isolated cases of hereditary sensory radicular neuropathy, and case 2 has been so described (Ogden et al., 1959). There are, however, distinguishing features some of which have now become apparent in case 2. Hereditary sensory radicular neuropathy (Table I) (Thévenard, 1942; Denny-Brown, 1951; Heller and Robb, 1955; Reimann et al., 1958; Mandell and Smith, 1960) characteristically develops in the second, third, and fourth decades, and its occurrence as a familial condition in many generations indicates a Mendelian dominant factor in its inheritance. Very occasionally the disease may present at an earlier age. Thévenard (1953) stated that the lowest age at presentation is 5 years, though Heller and Robb (1955) have since described a single family in which the onset in some members was at 2 years of age.

There is often destruction of joints, ulceration of the hands and feet, and loss of digits, and an early name for it was 'hereditary perforating ulcer of the foot' (Hicks, 1922). The lower limes only may be affected (Van Epps and Kerr, 1940). All modalities of sensation are involved and the sensory loss is greatest over the distal part of the limbs. The sensory loss progresses proximally until there is almost complete loss of sensation below the elbows and knees. Above these joints sensory loss is less severe and partial, and involves the trunk very exceptionally and incompletely (Thévenard, 1942). Cranial nerve involvement is unusual but auditory nerve involvement may occur. Biopsy of a peripheral nerve in an anaesthetic area shows degenerative changes and there is an absence of the flare reaction to the injection of intradermal histamine. The basic abnormality, at least in some families, is a degenerative condition of root ganglia (Denny-Brown, 1951; Van Bogaert, 1953).

\section{TABLE I}

DISTINGUISHING FEATURES OF CONGENITAL INDIFFERENCE TO PAIN AND HEREDITARY SENSORY RADICULAR NEUROPATHY COMPARED WITH FINDINGS IN CASES 1 AND 2

Present Patients

Early childhood

? Recessive

All

Limbs and trunk

Absent

Progressive

Peripheral neuropathy
Congenital Indifference to Pain

Early childhood

Sporadic ? Recessive

Pain only

Whole body

Normal

Static

?
Hereditary Sensory Radicular Neuropathy

Second to fourth decade

Dominant

All

Distal to elbows and knees

Absent distally

Progressive

Radicular neuropathy 
The patients described here are distinguishable from those with hereditary sensory radicular neuropathy (Table I). The three distinguishing features are: 1 Their disorder did not occur in other members of the family and inheritance therefore is probably not due to a dominant factor. In view of the consanguinity of the parents it may be due to a recessive factor. 2 The onset of symptoms was very early in life. 3 The condition has extended to involve the trunk.

\section{SUMMARY}

Two boys aged 10 years and 15 years are described. They each had consanguineous parents. They had a sensory neuropathy which did not belong to any of the generally recognized groups. It began in early childhood, progressed very gradually, involved all modalities of sensation, and was predominantly distal in distribution at first but later involved the trunk. It led to loss of digits and disorganization of the ankles. Physiological observations confirmed the loss of peripheral sensory axones in the anaesthetic areas but showed no evidence of motor or autonomic (sudomotor, piloerector, or vasomotor) disturbance.

One patient at first appeared to have absence of pain sense only, and in both the differential diagnosis from congenital indifference to pain was difficult at first. It later became clear, however, that they had a sensory neuropathy. Distinguishing features of their sensory neuropathy include involvement of sensory modalities other than pain, preservation of sensation including that of pain proximally, loss of tendon reflexes, gradual progression of the neurological abnormalities, and evidence of peripheral nerve degeneration.

The sensory neuropathy in these children is distinguished from hereditary sensory radicular neuropathy by absence of similar cases in the family, consanguinity of the parents, early age of onset, and ultimate extension to involve the trunk.

We wish to thank Dr. W. Ritchie Russell and Dr. C. W. M. Whitty for encouragement and advice and the following for expert assistance: Mr. J. D. Morgan and Dr. E. Brownell for biopsy examination, Mr. M. E. Humphrey for psychological testing, and Dr. J. Thorne for electromyographic studies: the departments of Biochemistry and Electroencephalography of United Oxford Hospitals. The Population Genetics Research Unit of the Medical Research Council kindly performed the chromosome studies.

One of us (R.H.J.) is in receipt of a grant from the
National Fund for Research into Poliomyelitis an£ Other Crippling Diseases.

\section{REFERENCES}

Bárány, F. R., and Cooper, E. H. (1956). Pilomotor and sudomoto innervation in diabetes. Clin. Sci., 15, 533-540.

Beçak, W., Beçak, M. L., and Schmidt, B. J. (1963). Chromosome trisomy of group 13-15 in two cases of generalized congenital analgesia. Lancet, 1, 664-665.

Berliner, K. (1940). Use of alpha-lobeline for measurement of velocity of blood flow. Arch. intern. Med., 65, 896-901.

Critchley, M. (1956). Congenital indifference to pain. Ann. intern? Med., 45, 737-747.

Dearborn, G. van Ness. (1932). A case of congenital general pure analgesia. J. nerv. ment. Dis., 75, 613-615.

Denny-Brown, D. (1948). Primary sensory neuropathy with muscula changes associated with carcinoma. J. Neurol. Neurosurga Psychiat., 11, 73-87. - (1951). Hereditary sensory radicular neuropathy. Ibid., 14

Durand, P., and Belotti, B. M. (1957). Un caso di indifferenzoु congenita al dolore. Helv. paediat. Acta, 12, 116-126.

Eyckmans, R., Radermecker, M. A., and Van Bogaert, L. (1956) Sur une ostéopathie congénitale mutilante assouée à ungy affection apparenté à l'acrodermatite atrophique. Res? neurol., 95, 37-47.

Fanconi, G., and Ferrazzini, F. (1957). Kongenitale analgie. Hel paediat. Acta, 12, 79-115.

Folkow, B. (1955). Nervous control of the blood vessels. Physion Rev., 35, 629-663.

Guttmann, L. (1940). Topographic studies of disturbances of sweat secretion after complete lesions of peripheral nerves. J. Neuroliv Psychiat., 3, 197-210.

Hatfield, H. S. (1950). A heat flow meter. J. Physiol. (Lond.), 111, 100 $11 \mathrm{P}$.

Head, H. (1903). Morvan's disease. Lond. Hosp. Gaz., 10, FinSuppl. p. 5 .

Heller, I. H., and Robb, P. (1955). Hereditary sensory neuropadny Neurology (Minneap.), 5, 15-29.

Hicks, E. P. (1922). Hereditary perforating ulcer of the foot. Laraet 1, 319-321.

Mandell, A. J., and Smith, C. K. (1960). Hereditary sensory radicula neuropathy. Neurology (Minneap.), 10, 627-630.

Munro, M. (1956). Sensory radicular neuropathy in a deaf childo Brit. med. J., 1, 541-544.

Ogden, T. E., Robert, F., and Carmichael, E. A. (1959). Some sensor syndromes in children: indifference to pain and sensor? neuropathy. J. Neurol. Neurosurg. Psychiat., 22, 267-276.

Parks, H., and Staples, O. S. (1945). Two cases of Morvan's syndrome of uncertain cause. Arch. intern. Med., 75, 75-81.

Reimann, H. A., McKechnie, W. G., and Stanisavljevic, S. (1958) Hereditary sensory radicular neuropathy and other defects in a large family. Amer. J. Med., 25, 573-579.

Silverman, F. N., and Gilden, J. J. (1959). Congenital insensitivity tōpain: a neurologic syndrome with bizarre skeletal lesions Radiology, 72, 176-190.

Thévenard, A. (1942). L'Acropathie ulcéro-mutilante familiale. Ret neurol., 74, 193-212.

(1953). L'Acropathie ulcéro-mutilante familiale. Acta neuroţ belg., 53, 1-24.

Van Bogaert, L. (1953). Etude histopathologique d'une observatio d'arthropathie mutilante symétrique familiale. Ibid., 53, 37-541957). Familial ulcers, mutilating lesions of the extremities, and acro-osteolysis. Brit. med. J., 2, 367-371.

Van Epps, C., and Kerr, H. D. (1940). Familial lumbosacral syringomyelia. Radiology, 35, 160-173.

Wadia, N. H., and Dastur, D. K. (1960). Congenital sensory neuro pathy. Wld Neurol., 1, 409-421.

Westlake, E. K. (1952). Congenital indifference to pain. Brit. med. J $1,144$.

Winkelmann, R. K., Lambert, E. H., and Hayles, A. B. (1962) Congenital absence to pain. Arch. Derm., 85, 325-339. 